\title{
Convertibility in Multi-Goal and Multi-Objective Optimization
}

\author{
Sukriti Gangwar ${ }^{1}$, Chandra Sen ${ }^{2}$ \\ ${ }^{1}$ Verily Life Sciences, San Francisco, USA \\ ${ }^{2}$ Department of Agricultural Economics, Institute of Agricultural Sciences, Banaras Hindu University, Varanasi, India \\ Email: sukritigangwar1411@gmail.com,chandra_sen@rediffmail.com
}

How to cite this paper: Gangwar, S. and Sen, C. (2022) Convertibility in Multi-Goal and Multi-Objective Optimization. American Journal of Operations Research, 12, 1117.

https://doi.org/10.4236/ajor.2022.121002

Received: December 14, 2021

Accepted: January 15, 2022

Published: January 18, 2022

Copyright (c) 2022 by author(s) and Scientific Research Publishing Inc.

This work is licensed under the Creative

Commons Attribution International

License (CC BY 4.0).

http://creativecommons.org/licenses/by/4.0/

\begin{abstract}
Multi-goal and multi-objective optimizations are similar techniques to achieve multiple conflicting goals/objectives simultaneously. There are several techniques for solving multi-goal and multi-objective optimization problems. The present study proposed the possibility of convertibility in solving multi-goal and multiobjective optimization problems.
\end{abstract}

\section{Keywords}

Multi-Goal Optimization, Multi-Objective Optimization, Individual Optimization

\section{Introduction}

The Multi-Goal Optimization (MGO) methods have been proposed [1] [2] [3] [4] to achieve the goals at their aspiration levels. The weighted sum of deviations between goals and their achievements is minimized to solve the MGO problems. Several variants of MGO [5] as Lexicographic goal programming and Integer goal programming have been widely used in various applications. In weighted sum MGO, the weights are assigned to all the goals as their per relative preference. Under Lexicographic MGO, the goals are ranked in order of their importance. Subjectivity in deciding the weights and priorities of goals was the major limitation of these methods. An improved MGO method was proposed by Sen in 2020 [6] to solve MGO problems efficiently. The improved MGO method is free from the problem of multi-dimensional aggregation of deviations in the goals and their achievements. The problem of high dimensional deviations in the goals is also reduced.

Multi-Objective Optimization (MOO) is also alternatively used for achieving multiple conflicting objectives. An appropriate method of MOO was proposed 
by Chandra Sen in 1982 [7] [8]. Sen's MOO method has been widely used for resource use planning in agriculture [9] [10] [11] [12] [13]. Several variants of MOO such as arithmetic mean, harmonic mean and geometric mean have been proposed [10]-[20] during the past four decades. The present study used MGP and MOP methods proposed by Sen for convertibility analysis. Both methods are explained below.

\section{Sen's Improved MGO Method}

\subsection{Basic Structure of Sen's Improved MGO Method}

The improved MGO method is described as:

$$
\text { Minimize } Z=\sum_{i=1}^{m}\left(d_{i}^{+}+d_{i}^{-}\right) / g_{i}
$$

Subject to:

Goal Constraints:

$$
\sum_{j=1}^{n} a_{i j} X_{j}-d_{i}^{+}+d_{i}^{-}=g_{i} \text { for } i=1, \cdots, m
$$

System constraints:

$$
\sum_{j=1}^{n} a_{i j} X_{j}=b_{i} \text { for } i=m+1, \cdots, p
$$

where: $g_{i}$ are $n$ goals to be achieved, $i=1,2, \cdots, m$.

There are " $m$ " Goals, " $p$ " System constraints and " $n$ " decision variables:

$Z=$ Objective function/Summation of all deviations;

$a_{i j}=$ the coefficient associated with $f^{\text {th }}$ variable in $t^{\text {th }} \mathrm{Goal} /$ constraint;

$X_{j}=$ the $f^{\text {th }}$ decision variable;

$g_{i}=$ the right hand side value of $I^{\text {th }}$ goal;

$b_{i}=$ the right hand side value of $i^{\text {th }}$ constraint;

$d_{i}^{-}=$negative deviational variation from $i^{\text {th }}$ goal (under achievement);

$d_{i}^{+}=$positive deviational variation from $i^{\text {th }}$ goal (over achievement).

\subsection{Conversion of MGO to MOO Method}

$$
\begin{gathered}
Z_{i}=\left[g_{i}, g_{2}, \cdots, g_{m}\right] \\
\text { Max. } Z=\sum_{i=1}^{r} \frac{Z_{i}}{g_{i}}-\sum_{j=r+1}^{m} \frac{Z_{j}}{g_{j}}
\end{gathered}
$$

Subject to:

$$
\begin{gathered}
A X \geq / \leq /=b \\
X \geq 0
\end{gathered}
$$

where;

$Z_{j}$ are the goals to be achieved.

The combined objective function has been formulated with the scalarized objective functions by their respective goals. 


\section{Multi-Objective Optimization (M00) Method}

\subsection{Basic Structure of MOO Method}

$$
\begin{gathered}
\text { Max. } Z_{i}=\left[Z_{1}, Z_{2}, \cdots, Z_{r}\right] \text { and Min. } Z_{j}=\left[Z_{r+1}, \cdots, Z_{m}\right] \\
\text { Max. } Z=\sum_{i=1}^{r} \frac{Z_{i}}{\theta_{i}}-\sum_{j=r+1}^{m} \frac{Z_{j}}{\theta_{j}}
\end{gathered}
$$

Subject to:

$$
\begin{gathered}
A X \geq / \leq /=b \\
X \geq 0
\end{gathered}
$$

where:

$Z_{i}$ and $Z_{j}$ are the objective functions to be maximized and minimized respectively;

$\theta_{i}$ and $\theta_{j}$ are the individual optima of $I^{\text {th }} \& f^{\text {th }}$ objective function.

\subsection{Conversion of MOO to MGO Method}

$$
\text { Minimize } Z=\sum_{i=1}^{m}\left(d_{i}^{+}+d_{i}^{-}\right) / \theta_{i}
$$

Subject to:

Goal Constraints:

$$
\sum_{j=1}^{n} a_{i j} X_{j}-d_{i}^{+}+d_{i}^{-}=\theta_{i} \text { for } i=1, \cdots, m
$$

System constraints:

$$
\sum_{j=1}^{n} a_{i j} X_{j}=b_{i} \text { for } i=m+1, \cdots, p
$$

where: $g_{i}$ are $n$ goals to be achieved, $i=1,2, \cdots, m$.

There are " $m$ " Goals, " $p$ " System constraints and " $n$ " decision variables:

$Z=$ Objective function/Summation of all deviations;

$a_{i j}=$ the coefficient associated with $f^{\text {th }}$ variable in $I^{\text {th }}$ Goal/constraint;

$X_{j}=$ the $f^{\text {th }}$ decision variable;

$\theta_{i}=$ the right hand side value of $I^{\text {th }}$ goal;

$b_{i}=$ the right hand side value of $i^{\text {th }}$ constraint;

$d_{i}^{-}=$negative deviational variation from $t^{\text {th }}$ goal (under achievement);

$d_{i}^{+}=$positive deviational variation from $I^{\text {th }}$ goal (over achievement).

\section{Examples}

\subsection{Solving MGO Problem in MOP Mode}

\section{Example 1:}

Goal $Z_{1}=6 X_{1}+9 X_{2}+3 X_{3}+8 X_{4}+4 X_{5} \geq 42$

Goal $Z_{2}=400 X_{1}+300 X_{2}+700 X_{3}+600 X_{4}+500 X_{5} \geq 3200$

Goal $Z_{3}=14 X_{1}+16 X_{2}+15 X_{3}+12 X_{4}+11 X_{5} \leq 50$ 
Goal $Z_{4}=70 X_{1}+100 X_{2}+95 X_{3}+80 X_{4}+90 X_{5} \leq 300$

Subject to:

$$
\begin{gathered}
X_{1}+X_{2}+X_{3}+X_{4}+X_{5}=5 \\
X_{1} \geq 1 \\
2 X_{4} \geq 1 \\
X_{1}, X_{2}, X_{3}, X_{4}, X_{5} \geq 0
\end{gathered}
$$

\section{Solution:}

Example 1 was solved by scalarizing the objective functions by respective goals as suggested in the methodology. The example has also been solved using Sen's MOO method for comparative analysis. The results are presented in Table 1.

The results of individual optimization of all the four goals are different indicating the conflicts amongst goals. All the four goals have been achieved as 41.5, 4150, 58.50 , and 355 which are very close to their goals of 42, 3200, 50, and 300 respectively. However, these solutions are all different. The results of the MGO method in MOO mode are the same. The achievements of the goals were 38, 2800, 62, and 390 with respect to their targets of 40,3000,60, and 300. All four goals have been achieved to their acceptable levels.

\subsection{Solving MO0 Problem in MGO Mode}

\section{Example 2:}

$$
\begin{gathered}
\text { Max. } Z_{1}=370 X_{1}+550 X_{2}+450 X_{3}+500 X_{4} \\
\text { Max. } Z_{2}=90 X_{1}+60 X_{2}+70 X_{3}+80 X_{4} \\
\text { Max. } Z_{3}=25 X_{1}+20 X_{2}+35 X_{3}+30 X_{4}
\end{gathered}
$$

Subject to:

$$
\begin{gathered}
X_{1}+X_{2}+X_{3}+X_{4}=7.5 \\
X_{2} \geq 0.5 \\
X_{1}, X_{2}, X_{3}, X_{4} \geq 0
\end{gathered}
$$

\section{Solution:}

The MOO problem was solved using Sen's MOO method and MGO mode. All the objectives have been optimized individually also. The results are presented in Table 2 .

It is clear from Table 2 that the maximum values of the first, second, and third objective functions are 4125, 660, and 255 respectively. All the three solutions of individual optimization are different and indicate the presence of conflicts amongst objectives. For solving this MOO problem in MGO mode, the goals for each objective function are decided. Values nearer (greater or lesser) to individual optima have been fixed as goals for solving the problem in MGO mode. The goals have been fixed as 4200, 700, and 300, for the first, second, and third objectives respectively. The problem was solved in MGO mode and the MOO method also for the comparative analysis. The results of the MOO problem 
Table 1. Solution of MGO problem solved by MGO and MOO mode.

\begin{tabular}{|c|c|c|c|c|c|c|}
\hline \multirow{3}{*}{$\begin{array}{l}\text { Item } \\
\text { Goals }\end{array}$} & \multicolumn{4}{|c|}{ Individual Goal Optimization } & \multirow{3}{*}{$\begin{array}{l}\text { MGO } \\
\text { Method }\end{array}$} & \multirow{3}{*}{$\begin{array}{l}\text { MOO } \\
\text { Mode }\end{array}$} \\
\hline & \multirow{2}{*}{$\begin{array}{l}Z_{1} \\
42\end{array}$} & \multirow{2}{*}{$\frac{Z_{2}}{3200}$} & \multirow{2}{*}{$\begin{array}{l}Z_{3} \\
50\end{array}$} & \multirow{2}{*}{$\begin{array}{c}Z_{4} \\
300\end{array}$} & & \\
\hline & & & & & & \\
\hline$X_{i}$ & $\begin{array}{c}1,3.5,0 \\
0.5,0\end{array}$ & $\begin{array}{c}1,0,3.5 \\
0.5,0\end{array}$ & $\begin{array}{c}1,0,0 \\
0.5,3.5\end{array}$ & $\begin{array}{c}4.5,0,0 \\
0.5,0\end{array}$ & $\begin{array}{c}1,0,0 \\
4,0\end{array}$ & $\begin{array}{c}1,0,0, \\
4,0\end{array}$ \\
\hline$Z_{1}$ & 41.5 & 20.50 & 24 & 31 & 38 & 38 \\
\hline$Z_{2}$ & 1750 & 3150 & 2450 & 2100 & 2800 & 2800 \\
\hline$Z_{3}$ & 76 & 72.50 & 58.50 & 69 & 62 & 62 \\
\hline$Z_{4}$ & 460 & 442.50 & 425 & 355 & 390 & 390 \\
\hline
\end{tabular}

Table 2. Solution of MOO problem solved by MOO and MGO mode.

\begin{tabular}{cccccc}
\hline \multirow{2}{*}{ Item } & \multicolumn{3}{c}{ Individual Optimization } & & \\
\cline { 2 - 5 } & Max. $Z_{1}$ & Max. $Z_{2}$ & Min. $Z_{3}$ & & \\
\hline$X_{i}$ & $0,7.5,0,0$ & $7,0.5,0,0$ & $0,0.5,7,0$ & $0,0.5,0,7$ & $0,0.5,0,7$ \\
$Z_{1}$ & 4125 & 2865 & 3425 & 3775 & 3775 \\
$Z_{2}$ & 450 & 660 & 520 & 590 & 590 \\
$Z_{3}$ & 150 & 185 & 255 & 220 & 220 \\
\hline
\end{tabular}

solved in MGO mode are very clear that all three objectives have been achieved simultaneously. The results indicate that both the methods for solving MGO or MOO problems are equally efficient.

\section{Conclusion}

The present analysis has been carried out to explore the possibilities of solving MGO problems using the MOO method and vice versa. Two suitable examples have been solved using modified methodologies. The solutions of proposed modified optimizations are very encouraging and shall be highly useful in various applications.

\section{Conflicts of Interest}

The authors declare no conflicts of interest regarding the publication of this paper.

\section{References}

[1] Charnes, A. and Cooper, W.W. (1961) Management Models and Industrial Applications of Linear Programming. John Wiley and Sons, New York.

[2] Charnes, A., Clower, R.W. and Kortanek, K.O. (1967) Effective Control through Coherent Decentralization with Preemptive Goals. Econometrica, 35, 294-320. https://doi.org/10.2307/1909114

[3] Hokey, M. and James, S. (1991) On the Origin and Persistence of Misconceptions in 
Goal Programming. Journal of Operational Research Society, 42, 301-312. https://doi.org/10.1057/jors.1991.68

[4] Ignizio, J.P. (1974) Generalized Goal Programming: An Overview. Computer and Operations Research, 10, 277-289. https://doi.org/10.1016/0305-0548(83)90003-5

[5] Lin, W.T. (1980) A Survey of Goal Programming Applications. Omega, 8, 115-117. https://doi.org/10.1016/0305-0483(80)90047-X

[6] Sen, C. (2020) Improved Multi-Goal Programming Technique. American Journal of Operational Research, 10, 45-48.

[7] Sen, C. (1982) An Integrated Multiperiod Rural Development Plan for Dwarahat Block, Almora, Uttar Pradesh-A Multiobjective Programming Approach. PhD. Thesis (Agricultural Economics), Department of Agricultural Economics, G. B. Pant University of Agriculture and Technology, Pantnagar.

[8] Sen, C. (1983) A New Approach for Multi-Objective Rural Development Planning. The Indian Economic Journal, 30, 91-96.

[9] Gangwar, L.S., Sen, C. and Pathak, A.D. (2021) Developing Optimal Cropping Plan for Small and Marginal Farms in Central Uttar Pradesh. International Journal for Modern Trends in Science and Technology, 7, 127-131.

[10] Gautam, K. (2013) Natural and Human Resource Use Planning for Vindhyan Region of Eastern Uttar Pradesh. Ph.D. Thesis, Department of Agricultural Economics, Institute of Agricultural Sciences, Banaras Hindu University, Varanasi.

[11] Kumar, H., Singh, R., Verma, S.C. and Pal, V.K. (2019) Multi-Objective Programming (MOP) Model for Aquaculture Production Systems in the Northern India. International Journal of Research in Engineering, Science and Management, 2, 295-298.

[12] Kumari, M., Singh, O.P. and Meena, D.C. (2017) Optimizing Cropping Pattern in Eastern Uttar Pradesh Using Sen's Multi-Objective Programming Approach. Agricultural Economics Research Review, 30, 285-291. https://doi.org/10.5958/0974-0279.2017.00049.0

[13] Maurya, M.K., Kamalvanshi, V., Kushwaha, S. and Sen, C. (2019) Optimization of Resources Use on Irrigated and Rain-Fed Farms of Eastern Uttar Pradesh: Sen's Multi-Objective Programming (MOP) Method. International Journal of Agricultural and Statistical Sciences, 15, 183-186.

[14] Sen, C. (2020) Improved Averaging Techniques for Solving Multi-Objective Optimization (MOO) Problems. SN Applied Sciences, 2, Article No. 286. https://doi.org/10.1007/s42452-019-1892-3

[15] Timothy, M.R. and Singh, A.J. (2004) Survey of Multi-Objective Optimization Methods for Engineering. Structural and Multidisciplinary Optimization, 26, 369-395. https://doi.org/10.1007/s00158-003-0368-6

[16] Sulaiman, N.A. and Abdulrahim, B.K. (2013) Using Transformation Technique to Solve Multi-Objective Linear Fractional Programming Problem. International Journal of Research and Reviews in Applied Sciences, 14, 559-567

[17] Huma, A., Geeta, M. and Sushma, D. (2017) Transforming and Optimizing Multi-Objective Quadratic Fractional Programming Problem. International Journal of Statistics and Applied Mathematics, 2, 1-5

[18] Nahar, S. and Alim, M.A. (2017) A New Statistical Averaging Method to Solve Multi-Objective Linear Programming Problem. International Journal of Science and Research, 6, 623-629

[19] Othman, A. and Ameen, H. (2017) An Adaptive Arithmetic Average Transformation Technique. LAMBERT Academic Publishing, Saarbrücken. 
[20] Sohag, Z.I. and Asadujjaman, M. (2018) A Proposed New Average Method for Solving Multi-Objective Linear Programming Problem Using Various Kinds of Mean Techniques. Mathematics Letters, 4, 25-33. https://doi.org/10.11648/j.ml.20180402.11 